\title{
Diagnosis and treatment of Chiari malformation type 1 in children: the International Consensus Document
}

\author{
Luca Massimi ${ }^{1}$ (D) Paola Peretta ${ }^{2}$ - Alessandra Erbetta ${ }^{3} \cdot$ Alessandra Solari $^{4} \cdot$ Mariangela Farinotti $^{4}$. \\ Palma Ciaramitaro ${ }^{5}$ - Veronica Saletti ${ }^{6}$ - Massimo Caldarelli ${ }^{1}$ - Alexandre Casagrande Canheu ${ }^{7} \cdot$ Carlo Celada $^{8}$. \\ Luisa Chiapparini ${ }^{3}$. Daniela Chieffo ${ }^{9}$. Giuseppe Cinalli ${ }^{10}$. Federico Di Rocco ${ }^{11}$. Marika Furlanetto ${ }^{12}$. \\ Flavio Giordano ${ }^{13} \cdot$ George Jallo $^{14} \cdot$ Syril James $^{15} \cdot$ Paola Lanteri $^{16} \cdot$ Christian Lemarchand $^{17}$. \\ Martina Messing-Jünger ${ }^{18}$. Cecilia Parazzini ${ }^{19}$ - Giovanna Paternoster ${ }^{15}$. Gianluca Piatelli ${ }^{20}$ - Maria. A. Poca ${ }^{21}$. \\ Prab Prabahkar ${ }^{22}$ - Federica Ricci ${ }^{23}$ - Andrea Righini ${ }^{19}$. Francesco Sala ${ }^{24}$ - Juan Sahuquillo ${ }^{21}$ - Marcus Stoodley ${ }^{25}$. \\ Giuseppe Talamonti ${ }^{26}$. Dominic Thompson ${ }^{27} \cdot$ Fabio Triulzi $^{28} \cdot$ Mino Zucchelli $^{29} \cdot$ Laura Valentini $^{12} \cdot$ International $^{2}$ \\ Experts - Jury of the Chiari \& Syringomyelia Consensus Conference, "Milan, November 11-13, 2019"
}

Received: 16 January 2021 / Accepted: 8 May 2021 / Published online: 7 June 2021

(C) The Author(s) 2021

\begin{abstract}
Background Chiari malformation type 1 (CM1) is a rare condition where agreed classification and treatment are still missing. The goal of this study is to achieve a consensus on the diagnosis and treatment of CM1 in children.

Methods A multidisciplinary panel formulated 57 provisional statements based on a review of the literature. Thirty-four international experts (IE) participated in a Delphi study by independently rating each statement on a 4-point Likert scale ("strongly disagree," "disagree," "agree," "strongly agree"). Statements that were endorsed ("agree" or "strongly agree") by < 75\% of raters were re-formulated, or new statements were added, and another Delphi round followed (up to a maximum of three).

Results Thirty-five IE were contacted and 34 agreed to participate. A consensus was reached on 30/57 statements (52.6\%) after round 1. Three statements were added, and one removed. After round 2, agreement was reached on 56/59 statements (94.9\%). Finally, after round 3, which took place during the 2019 Chiari Consensus Conference (Milan, Italy), agreement was reached on 58/59 statements (98.3\%) about four main sections (Definition and Classification, Planning, Surgery, Isolated Syringomyelia). Only one statement did not gain a consensus, which is the "definition of radiological failure 24 month post-surgery."

Conclusions The consensus document consists of 58 statements ( 24 on diagnosis, 34 on treatment), serving clinicians and researchers following children with CM1. There is a clear need for establishing an international network and registry and to promote collaborative studies to increase the evidence base and optimize the long-term care of this patient population.
\end{abstract}

Keywords Chiari 1 malformation · Syringomyelia $\cdot$ Consensus $\cdot$ Children $\cdot$ Craniovertebral decompression · Management

\section{Introduction}

Chiari malformation type 1 (CM1) has gained a great interest among the scientific community because of the continuously increasing number of diagnoses and several controversial issues, especially about definition, management, and outcome assessment. The literature is richer and

Luca Massimi

lucamax30@hotmail.com

Extended author information available on the last page of the article richer of papers, but in spite of some meta-analyses [1-6] and some international surveys [7-10], it still fails to achieve consensus as far as both methods and results are concerned. Moreover, no guidelines have been provided so far, although they are claimed by patients, Patients Associations, and physicians. These problems have to be faced both in affected children and adults.

This paper reports and comments on the results of the International Consensus Conference held in Milan in November 2019 with regard to the pediatric population. The goal of this meeting was to find a consensus among international experts on the most controversial issues to clear the way for creating guidelines. 


\section{Methods}

The results of the literature review (published in a separate article of the same issue) emphasized the necessity of a consensus strategy among the CM1 community. The parents of CM1 children, the Parental Associations, and the clinicians taking part in the diagnostic and treatment process further confirmed this need. Therefore, a panel of experts of the Chiari and Syringomyelia Consortium [11] formulated 57 draft statements on the main and controversial topics concerning CM1 and syringomyelia. A group of international experts (IE), from within and without Europe, designed by scientific production and by the Patients Associations, and with a cumulative experience of more about 8800 children (more than 3500 out of them were operated on), were asked to take part in the study as jury panelists.

The statements were distributed in a general addendum and in two separate questionnaires, one concerning pediatric patients and the other one adult patients. A Delphi process [12] was designed to reach a consensus of at least $75 \%$ of agreement. Three Delphi rounds were considered adequate as a reasonable effort to reach consensus among the experts. IE received a structured document to be voted on a 4-point Likert-type scale ("strongly disagree," "disagree," "agree," "strongly agree"). In each round, IE indicated their level of agreement on the proposed statements. Statements that did not gain consensus $(<75 \%$ of IE voting "agree" or "strongly agree") were redistributed to participants in rounds 2 and 3.

\section{Results and discussion}

This paper is focused on the results of the pediatric questionnaire and on the part of the general addendum addressing pediatric issues.

Thirty-five international experts (IE) were contacted and 34 agreed to participate in the Delphi process. The IE jury comprised 21 neurosurgeons, five neuro-radiologists, four pediatric neurologists, one neurologist, one psychologist, and two members of Patients Associations. A consensus was reached on 30 statements (52.6\%) after round 1 . Subsequently, three statements were added and one removed. After round 2, agreement was reached on 56 statements $(94.9 \%)$. The final discussion and voting took place during the Chiari Consensus Conference held in Milan, Italy, November 2019, with a $98.3 \%$ of final agreement (Fig. 1). Only one statement, regarding the definition of radiological failure after surgery at 24 months follow-up, remained under the requested agreement percentage (Fig. 2).

\section{Classification and definition}

This consensus conference arose from the ongoing work of an international task dedicated to the radiological classification and definition of CM1 and syringomyelia. An initial priority was to ensure that the panelists shared a common language. The agreement on the classification was as high as $85 \%$, which was considered adequate for the Consensus. The results are reported in detail in this issue in the article "Diagnosis and Treatment of Chiari Malformation and Syringomyelia in Adults: The International Consensus Document.”

In the absence of a better radiological definition, CM1 was considered herniation of one or both cerebellar tonsils $\geq 5 \mathrm{~mm}$ below McRae's line or even 3 to $5 \mathrm{~mm}$ but with syringomyelia or peg-like appearance of the tonsils. The transient tonsillar herniation resulting from hydrocephalus or other sources of mass effect is not considered CM1 but acquired tonsillar ectopia. Therefore, both the acquired tonsillar ectopia resulting from intracranial hypotension and intracranial hypertension should be ruled out with appropriate examinations, which are clinical pattern and contrast-enhanced MRI for CSF hypotension and clinical pattern, fundoscopy, and venous angio-MRI (or even direct ICP measurement, if needed) for raised ICP. Cough headache, signs and symptoms of brainstem and/or cerebellum and/or spinal cord dysfunction, otoneurological symptoms, and scoliosis remain the main findings composing the Chiari syndrome [13].

Syringomyelia and syringobulbia refer to longitudinally oriented fluid-filled cavities of any size respectively in the spinal cord and brain stem, expanding from the region of its largest diameter in the upper and/or lower direction. However, the definition, diagnosis, and classification of syringomyelia/ syringobulbia still raise many questions as not every fluidfilled cavitation of the spinal cord deserves the diagnosis of syringomyelia and the distinction between syringomyelia and central canal dilatation may be difficult [14-16]. Pending a better radiological definition and etiopathogenic classification, a classification distinguishing 4 types of syringomyelia is still used, type I-a being associated with CM1.

Patients with CM-I and syringobulbia/syringomyelia may have relevant symptoms because of the brainstem and spinal involvement. The most frequent syringobulbia-related symptoms, usually in a chronic pattern, are headache, gait and balance disorders, limb weakness or dysesthesia, IX and X cranial nerve dysfunction, persistent hiccup, oscillopsia, nystagmus, Horner syndrome, and central hypoventilation syndrome [17]. The typical clinical symptoms of syringomyelia consist of dysesthesia, sensory disturbances, or pain caused by maneuvers, such as Valsalva, cough, laughter, or sneezing in the corresponding dermatomes, while motor deficits tend to be a late symptom. A centrally positioned syrinx typically causes dissociated sensory loss, while a syrinx involving the posterior horns causes neuropathic pain, often described as a burning 
Fig. 1 Flowchart of the Delphi study

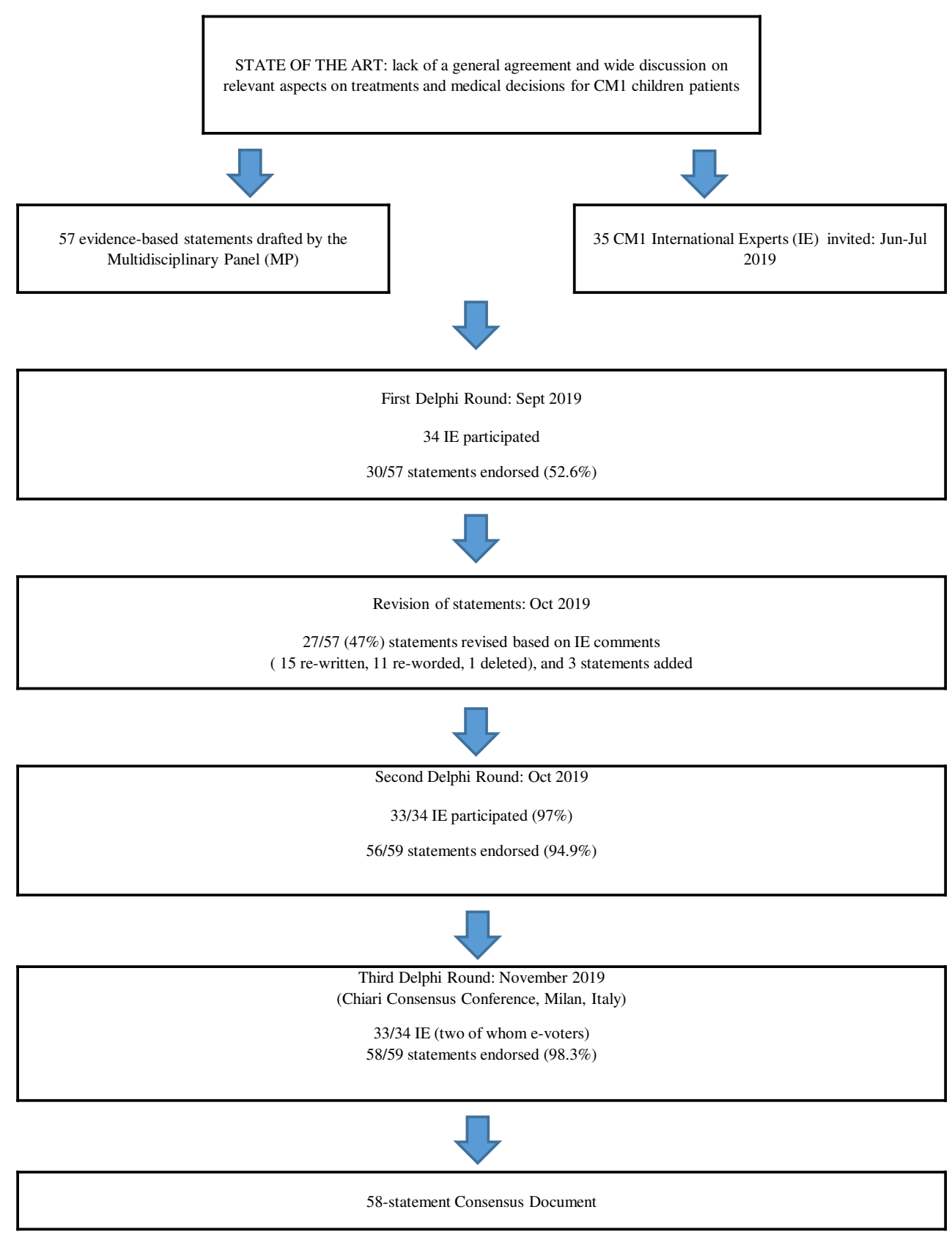

type of constant pain aggravated during resting periods [15, $18,19]$. Hydromyelia (thin, centrally located dilatation of the spinal cord) is usually found to be asymptomatic.

\section{Section 1-Planning for CM1 in children}

Table 1 summarizes the results of Part A: Indications to surgery This section strongly confirms conservative management in asymptomatic children without syringomyelia, even in case of significant tonsillar descent on MRI. Such an attitude already emerged in previous surveys, provided by the Pediatric Section of the American Association of Neurological Surgeons (2000) [8], by the International Society for
Pediatric neurosurgery $(2004,2018)[9,10]$, and by the Brazilian Society for Pediatric Neurosurgery (2020) [7]. This policy is reinforced by the rarity of abrupt and severe (posttraumatic) onset in previously asymptomatic patients [20-22]. The presence of syringomyelia is frequently considered the most important criteria for surgery in an asymptomatic patient as long as the syrinx is thicker than $5-8 \mathrm{~mm}$ or progressively enlarging. The cut-off ( $>5 \mathrm{~mm}$ or $>8 \mathrm{~mm}$ ) is still debated, and there is little evidence to correlate syringomyelia size with the presence of symptoms. However, the progression of syringomyelia seems to be more straightforward. The appearance of symptoms remains the main indication of surgery regardless of the size of the syrinx. 
Fig. 2 Agreement (\%) on each statement of the Children

Consensus Document in the three Delphi rounds (35 experts)

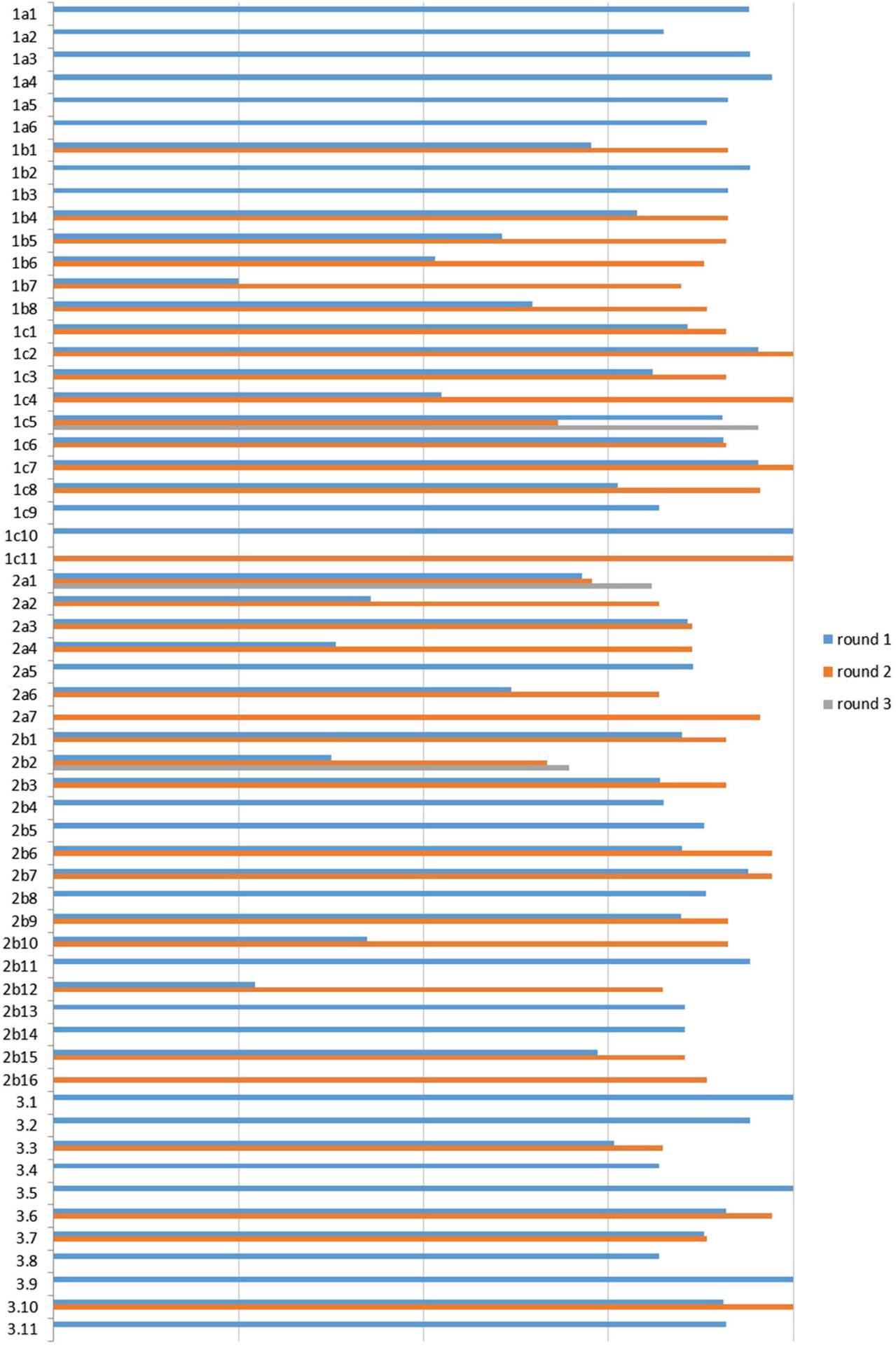

round 2

round 3
There is also a consensus that Chiari surgery should not be offered to children with CM1 and epilepsy as a means of improving seizure control. The high agreement on this topic results from both daily clinical practice and literature, based on the evidence that the association is random [23, 24]. Similarly, there is not an indication to operate on the CM1 in children with autism or other cognitive/behavioral disturbances since there is no evidence yet of correlations between the two conditions and, in particular, no evidence that the treatment of CM1 improves the behavior disorder [25-28]. However, in this subset of patients, a careful clinical and instrumental assessment is mandatory because the affected children may not be able to accurately report CM1 symptoms and clinical signs may be hard to detect. On these 
Table 1 Planning for CM1 in children: indications to surgery

\begin{tabular}{|c|c|c|}
\hline 1 & $\begin{array}{l}\text { In asymptomatic children with incidentally discovered, isolated CM1 and no syringomyelia, } \\
\text { surgery is not indicated }\end{array}$ & Agreement: $94.1 \%$ \\
\hline & $\begin{array}{l}\text { In asymptomatic children with incidentally discovered CM1 and syringomyelia, surgery is } \\
\text { indicated in cases of syrinx larger than } 5-8 \mathrm{~mm} \text {, and smaller syrinx increasing in size }\end{array}$ & Agreement: $82.4 \%$ \\
\hline & In children with epilepsy and CM1, surgical treatment of CM1 does not improve the seizure disorder & Agreement: $94.1 \%$ \\
\hline & $\begin{array}{l}\text { In children with CM1 and cognitive and/or behavioral disorders (such as autism) not able to correctly } \\
\text { report their symptoms because of communication impairment, careful clinical and instrumental } \\
\text { assessments are mandatory to detect symptoms and signs of cerebellar tonsils ectopia }\end{array}$ & Agreement: $97.1 \%$ \\
\hline & $\begin{array}{l}\text { In children with CM1 and cognitive and/or behavioral disorders (such as autism) and no clear CM1 } \\
\text { symptoms, surgery is not indicated to improve the clinical picture }\end{array}$ & Agreement: $91.2 \%$ \\
\hline & $\begin{array}{l}\text { Surgical treatment is not decided on MRI pattern in asymptomatic children with tonsillar ectopia } \geq 20 \mathrm{~mm} \\
\text { without syringomyelia }\end{array}$ & Agreement: $88.2 \%$ \\
\hline
\end{tabular}

grounds, autistic children who are symptomatic for CM1 and who undergo successful surgery can show an improvement in their cognitive and behavioral performances, but this results from the reduction of pain or other misdiagnosed symptoms. Some reports investigating the role of genetic mutations in isolated cases showed that the association between CM1 and autism and/or epilepsy is occasional, except for very rare and specific syndromes [29-32]. According to the experience of some panelists, the ventral compression of the basilar artery (due to dens malposition) may overt seizures or cognitive deficits related to raised ICP.

\section{A synopsis of the results of Part B: Symptoms and follow-up is} reported in Table 2 This section addresses the problem of the follow-up in asymptomatic subjects and the management of symptoms in the symptomatic ones. As far as the first group is concerned, there is agreement on the follow-up children with an incidental diagnosis of CM-1 until the end of their growth. Actually, although CM1 and syringomyelia tend to remain silent in the majority of asymptomatic children, a clinical and/or radiological progression cannot be excluded in a minority of them [33-36]. Although some examples of schedule are quite widely accepted (e.g., controls at 1, 3, and 5 years), the clinical and radiological check-up should be tailored according to each patient. If MRI is planned, it should include both the brain and whole spinal cord.

In symptomatic children, the role of the pediatric neurologist seems to be crucial in achieving a correct indication to surgery. Firstly, it is important for the differential diagnosis between $\mathrm{CM} 1$ headache and migraine or headaches resulting from other conditions. Inadequate and inaccurate assessment of headache will result in a wrong indication for surgery [37, 38]. Several studies have attempted to address this topic and proposed criteria to correctly diagnose the Chiari headache (cough headache, Valsalva headache, occipital or suboccipital, lasting a few minutes) [39, 40]. Moreover, a careful neurological evaluation is mandatory to rule out comorbidities and to correctly understand complex children (such as those with behavior disorders).
The use of neurophysiological examinations (SSEPs, MEPs, AEPs) is not routine but should be driven by clinical and/or radiological criteria. These should not be considered firstline examinations and their role in the diagnosis and evaluation of CM1 is unproven. Additionally, in spite of their utility in case of brainstem or spinal cord involvement, their role in the intraoperative monitoring at the moment of positioning and during the posterior fossa decompression remains controversial $[41,42]$. Polysomnography is indicated to confirm the diagnosis of sleep apneas at any age, in particular in infants and small children with significant overcrowding of the posterior fossa. The occurrence of sleep-disordered breathing in children with CM1 is well-documented [43-45], and even a certain correlation between radiological and polysomnographic picture has been found [46].

\section{Part C: Associated malformations: the results are summarized} in Table 3 There was general agreement that, when present, hydrocephalus should be treated in the first instance reserving foramen magnum decompression for cases where symptoms persist in spite of adequately controlled ICP. The treatment of hydrocephalus is addressed first to restore the CSF pathways and to relieve from raised ICP (which is often also the main source of symptoms), thus limiting the risks of complications (cerebellar ptosis, pseudomeningocele) in case of following posterior fossa decompression [47]. Moreover, it has been demonstrated that many children undergoing the treatment for hydrocephalus by endoscopic third ventriculostomy show a significant improvement of the CM1/syringomyelia and so do not require any specific therapy for CM1 and the associated syrinx $[48,49]$.

Because of their etiopathogenetic role in acquired CM1, non-syndromic craniosynostoses (mainly oxycephaly but also posterior lambdoid and sagittal synostosis) have been universally assumed to be treated before than CM1, whose management should be considered only in case of persistent symptoms and clear resolution of the synostosis picture. It is worth reminding that the rate of symptomatic CM1 subjects with undiagnosed craniosynostosis (namely, scaphocephaly) can be surprisingly high (15.5\%) [50]. 
Table 2 Planning for CM1 in children: symptoms and followup
1 In asymptomatic children with incidentally discovered CM1 and no syringomyelia, neurological follow-up and whole neuraxis MRI should be performed until the end of growth, with a schedule based on clinical picture and degree of tonsils herniation.

2 Neuro-pediatric evaluation is mandatory in all children with CM1 and headache

3 Neuro-pediatric evaluation is mandatory in all children with CM1 and symptoms and/or signs of the brainstem, cerebellar, and/or cervical cord dysfunction to identify co-pathologies

4 Neuro-pediatric evaluation is mandatory in all children with CM1 and cognitive and/or behavioral disorders

5 Somatosensory evoked potentials (SEPS) may be used in CM1 children only in association with other tools (both clinical and instrumental)

6 Auditory evoked potentials (BAEPs) may be used in CM1 children only in association with other tools (both clinical and instrumental)

7 Motor evoked potentials (MEPs) may be used in CM1 children only in association with other tools (both clinical and instrumental)

8 Polysomnography is indicated in very young children ( $<6$ years), in case of suspected apneas, and in case of severe cerebellar tonsils descent
Agreement: $91.2 \%$

Agreement: $94.1 \%$

Agreement: $91.2 \%$

Agreement: $91.2 \%$

Agreement: $90.9 \%$

Agreement: $87.9 \%$

Agreement: $84.8 \%$

Agreement: $88.2 \%$
The same considerations apply to syndromic craniosynostoses, where the restoration of a proper cranial volume plays an important role. The association between syndromic craniosynostosis and CMI represents a complex interaction between intracranial volume, venous hypertension, disordered CSF circulation, and skull base abnormality. The management of CM1 in this instance needs to be evaluated in the wider context of craniofacial management. This is best dealt with by
Table 3 Planning for CM1 in children: associated malformations
In symptomatic children with CM1 and hydrocephalus, it is recommended to treat hydrocephalus first to relieve raised intracranial pressure and to avoid post-operatory complications. CM1 can be treated afterwards if symptoms do not disappear

2 In CM1 children with non-syndromic craniosynostosis (sagittal or lambdoid synostosis, oxycephaly), the craniosynostosis is better treated before the CM1

3 In infants with syndromic craniosynostosis and CM1, the surgery should first increase the cranial volume, with the proper vault remodeling for each syndrome

In case of persistent CM1, in children with syndromic craniosynostosis already submitted to cranioplasty, the surgical approach depends on the syndrome, cranial volume obtained by previous operations, posterior fossa volume, and CM1 symptoms/associated syringomyelia

$5 \quad$ In CM1 toddlers with polisynostosis and prevalent brachycephaly (and in selected cases in the other age classes), a posterior vault osteogenic distraction could be considered before performing a posterior fossa decompression

6 Angio-RM or angio-CT is mandatory to rule out anomalous subcutaneous drainage before craniovertebral decompression in CM1 children with syndromic craniosynostosis

$7 \quad \mathrm{CM} 1$ is rarely associated with dysraphisms*and tethered cord syndrome (*tethering of the medulla at any level due to split cord malformation, limited dorsal myeloschisis, retained medullary cord, terminal myelocystocele, conus lipomas, thickened, and fatty filum with a low-lying conus (below L3))

8 In the rare occurrence of CM1 in children with tethered cord syndrome, the de-tethering procedure should be performed to prevent neuro-urological deterioration and has no influence on CM1.

9 The association of CM1 with "occult tethered spinal cord" (a tethering syndrome with a specific urodynamic pattern with a conus normally positioned above L2) has never been demonstrated.

10 The intradural section of the filum terminale in CM1 children is recommended just to treat tethered cord syndrome and it plays no role in the management of a possible CM1 syndrome.

11 The extradural section of the filum terminale in CM1 children is not recommended either to treat tethered cord syndrome or for the management of a possible CM1 syndrome.
Agreement $90.9 \%$

Agreement: $100 \%$

Agreement: $90.9 \%$

Agreement: $100 \%$

Agreement: $95.2 \%$

Agreement: $90.9 \%$

Agreement: $100 \%$

Agreement: $95.2 \%$

Agreement: $81.8 \%$

Agreement: $100 \%$

Agreement: $100 \%$ 
specialist craniofacial teams. There is a high rate of clinical and radiological recurrence in this subset of patients, and in situations of clinical/radiological persistence of CM1, a new operation should be carefully weighted according to the syndrome and the results of the previous cranioplasty/craniofacial distraction. Should the CM1 picture be clearly predominant, it can be addressed directly if the intracranial hydrodynamics have been adequately optimized. The posterior osteogenic distraction, proposed by some authors in children with recurrent CM1 [51], should be limited to patients with synostotic brachycephaly. In these children, the posterior distraction is likely to cure both the craniosynostosis and the associated CM1. Should a posterior fossa decompression be needed in syndromic children, a careful preoperative workup based on angio-RM is mandatory to rule out anomalous venous drainages and for a correct surgical planning [52].

The association between CM1 and the tethered cord is frequently debated in clinical practice and in the literature mainly because of the postulated "occult tethered cord syndrome" [7]. We found strong consensus on this topic: (1) the association between CM1 and the "true" or "manifest" tethered cord is universally found to be very rare and occasional [53]; (2) in those rare instances where a tethered cord syndrome is present in CM1 subjects, a de-tethering procedure is successfully performed to cure the syndrome but does not produce effects on the CM1 [54]; (3) the occult tethered cord syndrome remains a controversial and questionable entity [55] and more than $80 \%$ of panelists questioned its existence; (4) in case of symptomatic tethered cord, an intradural section of the filum terminale is recommended. The patient and his/her family should be aware that this operation is not addressing the associated CM1 [56, 57]; (5) the international experts were not aware of any evidence to support the use of the extradural section of the filum for either tethered cord syndrome or CM1.

\section{Section 2-Surgery for $\mathrm{CM} 1$ in children}

The results of Part A: Surgical techniques are reported in Table 4 The most appropriate surgical paradigm to treat pediatric CM1 is one that reflects the etiological heterogeneity of this condition. Once predisposing factors such as hydrocephalus have been dealt with, foramen magnum decompression remains the mainstay of treatment. In the literature, there are a large number of meta-analyses addressing the relative merits of bone-only decompression of the posterior fossa and decompression with duraplasty [1-6]. Most of these articles recently appeared (last 5 years) and report on a large number of patients, sometimes composing purely pediatric series or, more often, mixed series. Almost invariably, the comparison between the two techniques shows that the bony decompression alone has a very low rate of complications but a lower success rate; conversely, the duraplasty ensures better results but with a higher rate of complications (namely, the CSF-leakage- related ones). Accordingly, bony decompression is suggested in children without syringomyelia (and without severe symptoms), taking into account a possible risk of symptom recurrence. On the other hand, duraplasty is preferable when syringomyelia (and marked symptoms) is present, taking into account a certain risk of complications. The agreement on this is high but not complete ( $80 \%$ ), because some panelists prefer to perform the most radical treatment as the first step (duraplasty with or without tonsil coagulation) to avoid re-operations and to favor a quick resolution of the syringomyelia, while others do not accept the surgical risk of duraplasty and acknowledge the low improvement provided by the bony decompression alone. Several panelists suggested the use of intraoperative ultrasounds to determine the need for dural opening (duraplasty in case of suboptimal CSF flow and tonsils pulsations). The only prospective study available on this topic ( 82 adolescents, 40 treated by bony decompression and 42 by duraplasty) shows a similar clinical outcome and syrinx improvement between the two techniques, with longer operation times and hospital stay and higher risk of complication by duraplasty [58]. Subsequently, many panelists highlighted that the strategy "syringomyelia = duraplasty" should not be assumed as an absolute rule. Therefore, a small or an asymptomatic syrinx can be successfully managed by bony decompression alone, while a clearly symptomatic or a recurring one could require even a IV ventricle stent according to some authors.

A higher agreement (86.4-95.5\%) was reached in respect of the technical details. For bony decompression alone, the crucial region to be decompressed is that involving the bulbo-cevical region, which is represented by the foramen magnun and the $\mathrm{C} 1$ posterior arch that should be opened with resection of the transverse dural band at this level. The occipital squama should not be opened widely, to avoid the cerebellar ptosis; furthermore, extensive muscle strip and C2 laminectomy should be avoided where possible to reduce the risk of craniovertebral instability. Once again, the extent of the bone opening and its landmarks should be tailored to the characteristics of each patient. In the case of duraplasty, the subarachnoid space should not be violated (unless arachnoiditis is present) because this maneuver increases the risk of CSF leakage and arachnoid scarring. Similarly, the subpial coagulation of the tonsils should be limited to very low tonsillar ectopia (below $\mathrm{C} 2$ ) and/or recurrent syringomyelia and/or severe hindbrain dysfunction, since this maneuver adds some morbidity other than a risk of arachnoid scarring. A crucial point in the case of duraplasty is the dural closure, which should be capacious and watertight at the same time, possibly with non-resorbable stitches to ensure a longer endurance. In this context, both autologous grafts and allografts are suggested as a good option rather than artificial grafts. Although the latter are burdened by a higher risk of specific complications (foreign body reaction, systemic immune 
Table 4 Surgery for CM1 in children: techniques
1 In symptomatic CM1 children without syringomyelia, the bony decompression of the posterior fossa alone could be performed for the low complication rate, if the family accepts the perspective of possible second surgery

2 In CM1 children with syringomyelia, bony decompression + duraplasty is preferable

3 The extent of the bony decompression of the posterior fossa should be wide on the foramen, always including $\mathrm{C} 1$ laminectomy, and never extended to $\mathrm{C} 2$ for the risk of CVJ instability.

4 In CM1 without arachnoiditis, it is indicated to preserve the arachnoid membrane to avoid CSF leakage and delayed scarring

5 Cerebellar tonsils coagulation/resection is indicated in cases of very low-lying tonsils and recurrent or residual syringomyelia

6 Autologous and allograft dural patches are preferable to artificial graft; both are suitable, according to the surgeon's preference, while there are experiences suggesting to avoid the artificial ones

7 A watertight suture helps preventing CSF leakage, by non-resorbable stitches, together with a strict muscle and soft tissue closure.
Agreement:

$80.9 \%$

Agreement:

$81.8 \%$

Agreement: $86.4 \%$

Agreement: $86.4 \%$

Agreement: $86.4 \%$

Agreement: $81.8 \%$

Agreement: $95.5 \%$ response, premature graft dissolution, high costs), their use is widespread [59-61]. The technique of the closure is more important than the materials used to do it.

Part B: Surgical outcomes (Table 5) This section addresses one of the most heterogeneous aspects of the CM1 management, which is the definition and the assessment of the surgical outcome. A standardized method to evaluate the postoperative outcome for CM1 has not been widely embraced [62]. In clinical practice, the time to declare failure and the clinical and radiological criteria for failure may vary significantly in the different centers and, sometimes, among the members of the same center. Therefore, it is not surprising that this issue was the only point of "disagreement" (agreement < 75\%) registered among the panelists during the whole vote process. In spite of this, the definition of clinical surgical failure was widely accepted $(90.9 \%)$, being characterized by the persistence of symptoms 12 months after surgery. Such a period is usually sufficient to observe an improvement even after a bony decompression of the posterior fossa. The clinical evaluation is suggested also as a mandatory step for the early assessment of outcome (6 and 12 months from the operation) together with brain and spinal cord MRI. In this phase, cineMRI is regarded as helpful but not necessary in all cases. Instead, as mentioned, a sufficient agreement was not reached about the radiological definition of surgical failure. Actually, although the persistence of CM1 and syringomyelia 24 months after surgery seems a reasonable criterion, several panelists refused to separate the radiological from the clinical assessment. Moreover, a certain disagreement arose in defining time to failure, with one-half of panelists suggesting to reoperate a child for persistence of unchanged syrinx after 12 months (the stability of the syrinx was judged as a good outcome by the remaining panelists). As a result, the consensus was reached only when the definition of failure needing re- operation included worsening/persistence of clinical signs and/or symptoms, judged as the best way to assess the surgical outcome. Such a conclusion seems to conflict with the indication for surgery in asymptomatic, large syringomyelia (see Section 2, part A, question 2) and encourages (1) to define MRI criteria for failure, inclusive of functional studies of CSF spaces, and (2) to collect large multicenter series evaluated by comparable outcome scales.

Part C: Diagnosis and treatment of the main causes of surgical failure (Table 5) Apart from the wrong indication to surgery and the occurrence of complications (surgeon-related causes), some patient-related causes of failure have been reported in some series, such as comorbidities, unfavorable or complex anatomy, tonsils below $\mathrm{C} 2$, diameter of the spinal cord, and pediatric age (if compared with adulthood) [1, 63-65]. As far as the technique is concerned, the main cause of failure of the bony decompression alone is judged to be the too small bone opening/bone regrowth, especially at the level of the foramen magnum [66, 67]. In selected cases (where MRI is not clear enough), 3D CT scan may be helpful in estimating the extent of the decompression and in planning a new operation to enlarge the bone opening.

As far as duraplasty is concerned, incomplete expansion duraplasty, arachnoid scarring, and wound-related complications are the main factors negatively affecting the outcome $[65,67]$. Postoperative arachnoiditis is regarded as the most important cause of clinical and/or radiological recurrence. It can be addressed by a revision surgical procedure to perform a lysis of the adherences and/or to coagulate the tonsils (to gain space) or, in case of multiple recurrences, to stent the IV ventricle to maintain the patency of the obex [68]. The role of the IV ventricle stenting is still under debate.

Majority agreement was achieved regarding comorbidities which increase the risk of failed surgery independently from 


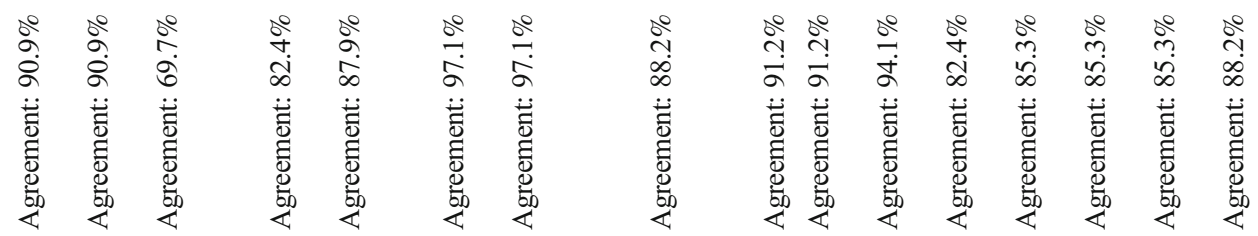
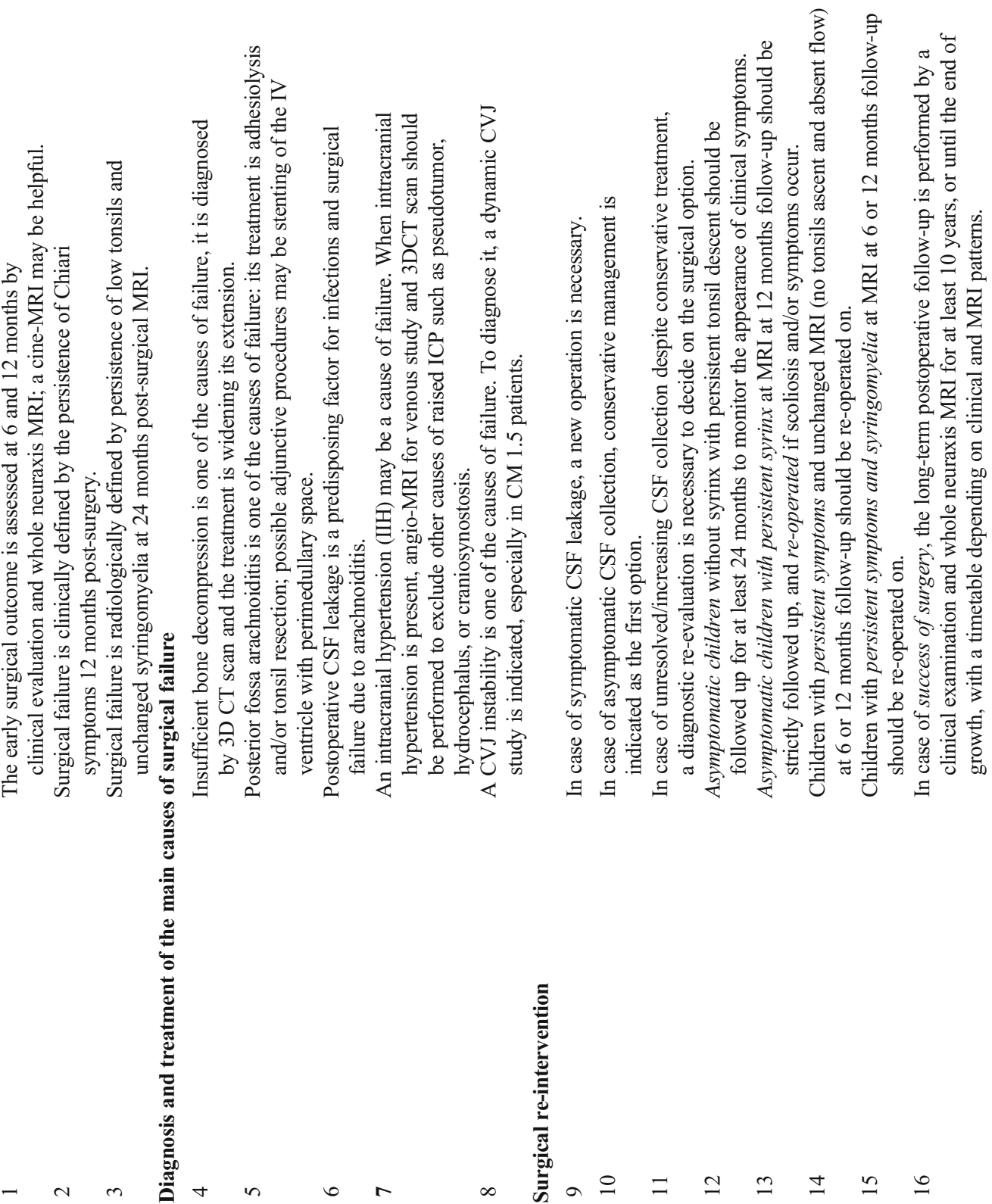
the used technique. Failure to appreciate and address important causative factors for Chiari such as raised intracranial pressure and craniovertebral instability is a predominant cause of treatment failure. The most feared complication is CSF leakage (which, though very rarely, can occur also after bony decompression alone) that is considered a predisposing factor for arachnoiditis (especially because of the resulting infective or aseptic meningitis). Raised ICP, on the other hand, is a possibly misdiagnosed cause of failure. If suspected, it should be ruled out clinically (fundoscopy, clinical history) and radiologically (angio-MRI in case of presumed pseudotumor cerebri, CT scan in case of craniosynostosis) to avoid unnecessary re-operations on CM1/syringomyelia. Similarly, an underestimated CVJ instability is likely to cause persistence of symptoms after surgery. Its role in the clinical picture should be properly addressed by clinical assessment and by a dynamic radiological study.

Part D: Surgical re-intervention (Table 5) This part was devoted to the management of the complications/comorbidities presented in part $\mathrm{C}$ and the failed surgery. The first 3 questions addressed the management of CSF leakage, which was differentiated between symptomatic (open CSF leak or painful, closed subcutaneous CSF collection) and asymptomatic (subcutaneous CSF collection that does not cause symptoms or esthetic impact). The true CSF leakages and the symptomatic CSF collections deserve an aggressive management, which is a surgical revision of the duraplasty and the surgical cavity (plus external lumbar drainage, if needed). On the other hand, a conservative management (diuretic therapy, steroids, bandage, wait and see) is advised in case of asymptomatic "closed" CSF collections. However, should the latter persist for a long time or increase, a new diagnostic work-up and, possibly, a re-operation have to be considered.

As mentioned, the radiologic persistence of tonsils ectopia is not felt to be a failure. Therefore, if asymptomatic and without syringomyelia, children with persistent radiological CM1 should only be followed up to rule out the appearance of symptoms. In the panelists' opinion, the minimum follow-up for recurrence of symptoms is 2 years after surgery but, more properly, it should be protracted till the end of the patient development. The same policy is advised for asymptomatic children with persistent syringomyelia (which means persisting at least 1 year after surgery). A new surgical operation is carried out in case of occurrence of symptoms or scoliosis. Scoliosis is actually found to be an active sign of CM1 with/without syringomyelia in several cases $[69,70]$.

A significant agreement was reached also about children with persistent symptoms and missed radiological improvement (CM1 and/or syringomyelia persisting 6 or 12 months after surgery): they should be re-operated on. Six months can be proposed as the minimum time to wait before the declaration of failure (to be shortened if the patient is severely symptomatic), while 12 months is the maximum one.

Finally, children who underwent a successful surgery are advised to be followed up until the end of growth or at least for 10 years, clinically and radiologically (at least one brain and
Table 6 Specific conditions related to CVJ malformations: surgical options
1 CM 1.5 may be associated with basilar invagination or impressio basilaris. Only cases with related symptoms need to be operated.

The preferred, etiological, surgical option for symptomatic basilar invagination associated with CM1 without atlanto-axial instability, could be anterior decompression, when posterior reduction has already failed.

3

The preferred surgical option for basilar invagination with atlanto-axial dislocation is posterior fixation.

4 Craniovertebral junction (CVJ) instability is a mobile dislocation between $\mathrm{C} 0, \mathrm{C} 1$, and $\mathrm{C} 2$ (according to neuro-radiological exams) leading to neuro axial compression, neurological deficits, progressive deformity, or structural pain.

5 The standard diagnostic work-up for CVJ instability in CM should include (other than MRI) dynamic X-rays + dynamic CT scan with 3D reconstructions.

$6 \mathrm{CVJ}$ fixation, with or without posterior decompression, is not indicated in CM1 patients without a documented CVJ instability.

7 Posterior decompression and CVJ fixation is the preferred surgical option for CM patient with CVJ instability and related symptoms.

8 In order to identify the best surgical option for CVJ instrumentation in a CM patient it is mandatory to identify the following: (A) the vertebral artery course by preoperative neuro-radiological studies (Angio-MRI, Angio-CT) and (B) the bone thickness of the occipital crest, the $\mathrm{C} 2$ isthmus diameter, the volume of $\mathrm{C} 3$ lateral masses.

9 To identify the best surgical option of $\mathrm{C} 1-\mathrm{C} 2$ instrumentation it is mandatory to define the following: (A) the vertebral artery course by preoperative imaging (angio-MRI, angio-CT) and (B) the $\mathrm{C} 2$ isthmus diameter

10 Fixations by $\mathrm{C} 0-\mathrm{C} 3$ or $\mathrm{C} 1-\mathrm{C} 2$ in $\mathrm{CM}$ patients with $\mathrm{CVJ}$ instability should be decided on the basis of local anatomy.

Agreement:
$95.2 \%$
Agreement:
$85.7 \%$
Agreement:
$100 \%$
Agreement:
$85.7 \%$
Agreement:
$81 \%$
Agreement:
$90.5 \%$
Agreement:
$90.5 \%$
Agreement:
$90.5 \%$

Agreement:
$85.7 \%$
Agreement:
$95.2 \%$

Agreement:

greement:

greement:

greement:

greement:

$90.5 \%$

Agreement:

greement:

$90.5 \%$

$95.2 \%$ 
spinal cord MRI), to exclude recurrences. The frequency of the follow-up controls should be scheduled through a personalized plan.

Part E: Surgical options for specific conditions related to CVJ malformations (Table 6) A separate section was dedicated to the CVJ instability because of its still unclear relationship with CM1 and the still missing general agreement on its management, which is often different and even independent from CM1 [71-73]. Particularly controversial is the use of fixation to manage CM1 patients without CVJ anomalies [74].

A first, large agreement was achieved about the need to operate on only symptomatic subjects with basilar invagination/impression basilaris-related CM 1.5. This result is apparently obvious, but in clinical practice, a certain trend to propose prophylactic surgery emerged (probably due to the more severe radiological picture). As far as symptomatic basilar invagination without atlanto-axial instability is concerned, the proposed option is to attempt a posterior reduction first and, in case of failure, to perform an etiologic treatment by anterior decompression (followed by posterior fusion). The option of the posterior reduction first, as observed by the panelists, allows also to rule out microinstability and to verify if the odontoid is reducible, thus avoiding anterior decompression, if unnecessary. On the other hand, subjects with symptomatic basilar invagination associated with atlanto-axial instability require treatment by reduction and posterior fixation, accepting that, in some instances, an anterior decompression may be indicated for persisting the compression with symptoms. The same option applies to children with CM1 associated with CVJ instability where, in addition, the posterior fossa decompression can be added. It was widely agreed that there is no indication for CVJ fixation in CM1 children if CVJ instability or hypermobility is not documented. Similarly, there was complete agreement to select the treatment (e.g., $\mathrm{C} 0-\mathrm{C} 3$ fixation versus $\mathrm{C} 1-\mathrm{C} 2$ fixation) based on the anatomical condition and the instability and not on the personal belief of the surgeon.

On these grounds, some questions were devoted to the definition (question 4) and the diagnostic work-up of CVJ instability (questions $5,8,9$ ). The proposed definition includes also the clinical findings because instability is not ever easy to demonstrate radiologically. A good agreement was achieved about the need to perfect the diagnosis of CVJ instability with dynamic 3D CT scan (thus, not only by dynamic Xrays) and to carefully investigate the course of the vertebral artery and the volume and morphology of the occipital squama and cervical vertebrae prior to surgery. This appears particularly pertinent in children, where the anatomical conditions may vary significantly according to age. For the "simple" diagnosis, on the other hand, dynamic X-rays and MRI are enough (so that the load of CT-related X-rays is avoided).
Section 3-Isolated/non-CM1 pediatric syringomyelia

Part A: Differential diagnosis (Table 7) As shown, syringomyelia is frequently associated with CM1 and it is a discriminating factor influencing the indication for surgery and the assessment of outcome [75-77]. Its management is strictly related to the management of CM1. On the other hand, nonCM1 syringomyelia, which is likewise frequent, deserves a separate dissertation because of its varied etiology and management. In this context, the first crucial step to be addressed is the differential diagnosis. Since this type of syringomyelia is often clinically silent, such a differential diagnosis is obtained radiologically. A general agreement was expressed on the need for a whole spinal cord MRI to rule out associated anomalies (namely, but not only, spinal dysraphisms). A high agreement was also reached on the need for contrast medium administration to rule out associated tumors (or vascular malformations). Similarly, MRI with CISS-sequences or, in very selected cases, myelo-CT scan can be considered useful to detect small arachnoid cysts or the signs of arachnoiditis, although the latter diagnosis may be hard to obtain and the sensitivity of these techniques is not absolute. Finally, the need for dynamic studies in case of suspected CVJ or spine instability was reaffirmed.

Part B: Surgical indications (Table 7) As for CM1, there is no reason to operate on children with asymptomatic, isolated, and stable syringomyelia (universal agreement), based on the low reported risk of evolution [35, 78-80]. In this instance, it is advised to perform a clinical and radiological follow-up, according to the characteristics of each patient. On the other hand, in case of appearance of symptoms and/or clear radiological progression and/or neurophysiological deterioration, surgery is indicated. It is worth noting that, in pediatric cases, scoliosis is considered a possible marker of syringomyelia progression [13]. Of course, to be considered an indication for surgery, the scoliosis progression should be associated with a large syrinx (not with idiopathic hydromyelia, which is commonly coupled with scoliosis).

Part C: Surgical technique options (Table 7) This conclusive part addresses the surgical options according to the different settings possibly associated with non-CM1 syringomyelia. The need to perform treatment directed according to etiology is strongly confirmed. As a consequence, syringomyelia associated with spinal dysraphism should be treated by de-tethering of the spinal cord, while that related to spinal cord tumors by excision of the tumor. Similarly, the challenging syringomyelia resulting from post-traumatic or post-surgical arachnoiditis should be treated by lysis of the adherences when symptomatic or progressive. In the case of post-traumatic/post-surgical arachnoiditis, the surgical results may be disappointing; 


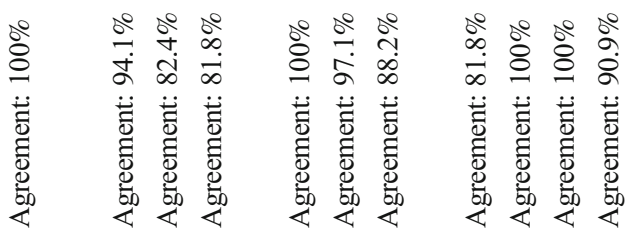

therefore, lysis should be planned only in case of clearly symptomatic patients. These results sound quite obvious; however, they definitively affirm the important concept that a direct treatment of syringomyelia is not routinely necessary nor advised. Indeed, a direct approach (e.g., shunting) is required only in case of failure of the etiologic treatment [81].

\section{Conclusions}

The consensus process on the controversial topics in children was fruitful and allowed the authors to get some results that can be used as a base for future studies looking for recommendations or guidelines. They can be summarized as follows:

(1) The old definition of CM1 is still accepted, although the definition based on level of descent in millimeters alone has little clinical correlation. Attention must be paid not only on the degree of tonsillar descent but also to the morphology and volume of the posterior fossa. Transient tonsillar descent resulting from remitting primary diseases is not a CM1. Syringomyelia is considered if large and/or progressing and/or symptomatic (thin hydromyelia is a para-physiological finding);

(2) No surgical indications are recognized in asymptomatic children with CM1 but without syringomyelia;

(3) To date, no etiological relationship has been found between CM1 and epilepsy or autism;

(4) Asymptomatic children should remain in contact with their physicians until the end of their growth. If needed, clinical and radiological controls are scheduled according to the characteristics of each patient;

(5) Symptomatic subjects benefit from a multidisciplinary team to rule out symptoms/signs unrelated to CM1 (e.g., key role of the neurologist in case of migrainelike headache). Some tools (polysomnography, SSEPs, MEPs) are useful in selected, doubtful cases;

(6) In CM1 with associated hydrocephalus, hydrocephalus should be treated first to reduce the intracranial pressure, limiting the posterior fossa decompression to the children with persisting symptoms;

(7) CM1 can result from both non-syndromic and syndromic craniosynostoses whose treatment needs to be incorporated into the treatment strategy. Cranial vault surgery may address cerebellar ectopia. The posterior fossa decompression or the posterior distraction should be limited to selected cases;

(8) Tethered cord is rarely and sporadically associated with CM1 and its management is independent of CM1. A manifest and symptomatic tethered cord is treated by intradural de-tethering but no effects on CM1 are expected; 
(9) Bony posterior decompression and duraplasty are both acceptable techniques of foramen magnum decompression. The first offers a very low rate of complications and a short hospital stay but shows a higher risk of persisting symptoms: it can be considered in children without severe symptoms or large syringomyelia. The second one ensures more consistent radiological results but with a higher rate of (CSF-related) complications;

(10) The bony decompression has to be focused on a proper opening of the foramen magnum and $\mathrm{C} 1$ (no need for large opening of the occipital squama or $\mathrm{C} 2$ );

(11) The key points of duraplasty are to keep unviolated the arachnoid plane and to perform a proper dural closure (no need of tonsils coagulation unless this appears necessary to effect an effective and capacious decompression: e.g., tonsils extending below $\mathrm{C} 2$ );

(12) The surgical failure can be defined by the persistence of symptoms 1 year after surgery. The radiological persistence of $\mathrm{CM} 1$ /syringomyelia should be interpreted in clinical context before a decision to re-operate;

(13) Too small opening and incorrect indication are the main causes of failure of bony decompression alone. Reoperation with a larger decompression and duraplasty are the respective solutions;

(14) Arachnoiditis is an important cause of failure of duraplasty. Proper surgical technique, re-operation with arachnoid lysis, and, in very selected cases, IV ventricle stenting are the solutions;

(15) Asymptomatic postoperative CSF collection can be managed conservatively, while they should be treated promptly, if symptomatic;

(16) CVJ instability or craniovertebral deformity (basilar impression) must be ruled out in any (CM1) patient presenting with atypical clinical and/or radiological findings. Only symptomatic subjects should be treated, using a technique chosen according to the patient's characteristics. The posterior decompression for CM1 can be added in selected cases;

(17) Syringomyelia must be always ruled out in CM1 children by MRI of the whole spinal cord;

(18) Asymptomatic, isolated, and stable syringomyelia shows a very low risk of evolution (no operation is indicated in this instance). It may require treatment only if symptomatic and the treatment is etiological. The direct management (shunting) should be considered only after failure of the etiologic one.

Acknowledgements The authors would like to thank the following Patients Association for their participation and support (in alphabetical order): AICRA for Craniosynostosis (Italy), AISMAC (Italy), APAISER (France), ASAP (USA), Bobby Jones Chiari \& Syringomyelia Foundation (USA), Deutsche Syringomyelie und Chiari Malformation (Germany), FEMACPA (Spain), National Syringomyelia Association (Bulgaria), SACA (Ireland).
Author contribution All authors contributed to the study conception and design. Material preparation, data collection, and analysis were performed by Luca Massimi, Paola Peretta, Alessandra Erbetta, Alessandra Solari, Mariangela Farinotti, Palma Ciaramitaro, Veronica Saletti, and Laura Valentini. The first draft of the manuscript was written by Luca Massimi and Laura Valentini. All authors commented on previous versions of the manuscript. All authors read and approved the final manuscript.

Funding Open access funding provided by Università Cattolica del Sacro Cuore within the CRUI-CARE Agreement.

Availability of data and material Data is available at the reader's request.

Code availability Not applicable.

\section{Declarations}

Ethical approval Not applicable.

Consent to participate Not applicable.

Consent for publication Not applicable.

Conflict of interest The authors declare no competing interests.

Open Access This article is licensed under a Creative Commons Attribution 4.0 International License, which permits use, sharing, adaptation, distribution and reproduction in any medium or format, as long as you give appropriate credit to the original author(s) and the source, provide a link to the Creative Commons licence, and indicate if changes were made. The images or other third party material in this article are included in the article's Creative Commons licence, unless indicated otherwise in a credit line to the material. If material is not included in the article's Creative Commons licence and your intended use is not permitted by statutory regulation or exceeds the permitted use, you will need to obtain permission directly from the copyright holder. To view a copy of this licence, visit http://creativecommons.org/licenses/by/4.0/.

\section{References}

1. Chai Z, Xue X, Fan H, Sun L, Cai H, Ma Y, Ma C, Zhou R (2018) Efficacy of posterior fossa decompression with duraplasty for patients with Chiari malformation type I: a systematic review and meta-analysis. World Neurosurg 113:357-365

2. Durham SR, Fjeld-Olenec K (2008) Comparison of posterior fossa decompression with and without duraplasty for the surgical treatment of Chiari malformation type I in pediatric patients: a metaanalysis. J Neurosurg Pediatr 2:42-49

3. Lin W, Duan G, Xie J, Shao J, Wang Z, Jiao B (2018) Comparison of results between posterior fossa decompression with and without duraplasty for the surgical treatment of Chiari malformation type I: a systematic review and meta-analysis. World Neurosurg 110:460-474

4. Lu VM, Phan K, Crowley SP, Daniels DJ (2017) The addition of duraplasty to posterior fossa decompression in the surgical treatment of pediatric Chiari malformation type I: a systematic review and meta-analysis of surgical and performance outcomes. J Neurosurg Pediatr 20:439-449

5. Xu H, Chu L, He R, Ge C, Lei T (2017) Posterior fossa decompression with and without duraplasty for the treatment of Chiari 
malformation type I-a systematic review and meta-analysis. Neurosurg Rev 40:213-221

6. Zhao JL, Li MH, Wang CL, Meng W (2016) A systematic review of Chiari I malformation: techniques and outcomes. World Neurosurg 88:7-14

7. Canheu AC, Santos MV, Furlanetti LL, Salomão JFM, de Oliveira RS (2020) The Brazilian Society for Pediatric Neurosurgery: consensus on Chiari I deformity. Childs Nerv Syst 36:17-18

8. Haroun RI, Guarnieri M, Meadow JJ, Kraut M, Carson BS (2000) Current opinions for the treatment of syringomyelia and Chiari malformations: survey of the Pediatric Section of the American Association of Neurological Surgeons. Pediatr Neurosurg 33:311-317

9. Schijman E, Steinbok P (2004) International survey on the management of Chiari I malformation and syringomyelia. Childs Nerv Syst 20:341-348

10. Singhal A, Cheong A, Steinbok P (2018) International survey on the management of Chiari 1 malformation and syringomyelia: evolving worldwide opinions. Childs Nerv Syst 34:1177-1182

11. Ciaramitaro P, Garbossa D, Peretta P, Piatelli G, Massimi L, Valentini L, Migliaretti G, Baldovino S, Roccatello D, Kodra Y, Taruscio D (2020) Interregional Chiari and Syringomyelia Consortium; on behalf of the Interregional Chiari and Syringomyelia Consortium. Syringomyelia and Chiari Syndrome Registry: advances in epidemiology, clinical phenotypes and natural history based on a North Western Italy cohort. Ann Ist Super Sanita 56:48-58

12. Ciaramitaro P, Cruccu G, de Tommaso M, Devigili G, Fornasari D, Geppetti P, Lacerenza M, Lauria G, Mameli S, Marchettini P, Nolano M, Polati E, Provitera V, Romano M, Solaro C, Tamburin S, Tugnoli V, Valeriani M, Truini A (2019) Neuropathic Pain Special Interest Group of the Italian Neurological Society. A Delphi consensus statement of the Neuropathic Pain Special Interest Group of the Italian Neurological Society on pharmacoresistant neuropathic pain. Neurol Sci 40:1425-1431

13. Bolognese PA, Brodbelt A, Bloom AB, Kula RW (2019) Chiari I malformation: opinions on diagnostic trends and controversies from a panel of 63 international experts. World Neurosurg 130:e9-e16

14. Blegvad C, Grotenhuis JA, Juhler M (2014) Syringomyelia: a practical, clinical concept for classification. Acta Neurochir 156:2127-2138

15. Klekamp J (2018) How should syringomyelia be defined and diagnosed? World Neurosurg 111:e729-e745

16. Milhorat TH (2000) Classification of syringomyelia. Neurosurg Focus 8:E1

17. Shen J, Shen J, Huang K, Wu Y, Pan J, Zhan R (2019) Syringobulbia in patients with Chiari malformation type I: a systematic review. Biomed Res Int 2019:4829102

18. Milhorat TH, Johnson RW, Milhorat RH, Capocelli AL Jr (1995) Pevsner PH (1995) Clinicopathological correlations in syringomyelia using axial magnetic resonance imaging. Neurosurgery 37 : 206-213

19. Milhorat TH, Kotzen RM, Mu HT, Capocelli AL Jr, Milhorat RH (1996) Dysesthetic pain in patients with syringomyelia. Neurosurgery 38:940-946

20. Massimi L, Della Pepa GM, Caldarelli M, Di Rocco C (2012) Abrupt clinical onset of Chiari type I/syringomyelia complex: clinical and physiopathological implications. Neurosurg Rev 35:321-329

21. Strahle J, Geh N, Selzer BJ, Bower R, Himedan M, Strahle M, Wetjen NM, Muraszko KM, Garton HJ, Maher CO (2016) Sports participation with Chiari I malformation. J Neurosurg Pediatr 17:403-409

22. Talamonti G, Marcati E, Gribaudi G, Picano M, D’Aliberti G (2020) Acute presentation of Chiari 1 malformation in children. Childs Nerv Syst 36:899-909

23. Granata T, Valentini LG (2011) Epilepsy in type 1 Chiari malformation. Neurol Sci 32 Suppl 3:S303-S306

24. Marianayagam NJ, Shalom NB, Zarchi O, Michowiz S, Margalit N, Rajz G (2020) Conservative management for pediatric patients with
Chiari 1 anomaly: a retrospective study. Clin Neurol Neurosurg 189:105615

25. Jayarao M, Sohl K, Tanaka T (2015) Chiari malformation I and autism spectrum disorder: an underrecognized coexistence. J Neurosurg Pediatr 15:96-100

26. Riva D, Usilla A, Saletti V, Esposito S, Bulgheroni S (2011) Can Chiari malformation negatively affect higher mental functioning in developmental age? Neurol Sci 32 Suppl 3:S307-S309

27. Rogers JM, Savage G, Stoodley MA (2018) A systematic review of cognition in Chiari I malformation. Neuropsychol Rev 28:176-187

28. Strahle J, Maher CO (2015) Letter to the Editor: Chiari malformation I and autism spectrum disorder. J Neurosurg Pediatr 16:609-610

29. Lumish HS, Wynn J, Devinsky O, Chung WK (2015) Brief Report: SETD2 mutation in a child with autism, intellectual disabilities and epilepsy. J Autism Dev Disord 45:3764-3770

30. Osuagwu FC, Amalraj B, Noveloso BD, Aikoye SA, Bradley R (2016) Autism spectrum disorder and Chiari 1 malformation cooccurring in a child. Tokai J Exp Clin Med 41:54-56

31. Saletti V, Esposito S, Maccaro A, Giglio S, Valentini LG, Chiapparini L (2017) Chiari I malformation in a child with PTEN hamartoma tumor syndrome: association or coincidence? Eur J Med Genet 60:261-264

32. Saletti V, Viganò I, Melloni G, Pantaleoni C, Vetrano IG, Valentini LG (2019) Chiari I malformation in defined genetic syndromes in children: are there common pathways? Childs Nerv Syst 35:1727-1739

33. Benglis D Jr, Covington D, Bhatia R, Bhatia S, Elhammady MS, Ragheb J, Morrison G, Sandberg DI (2011) Outcomes in pediatric patients with Chiari malformation type I followed up without surgery. J Neurosurg Pediatr 7:375-379

34. Novegno F, Caldarelli M, Massa A, Chieffo D, Massimi L, Pettorini B, Tamburrini G, Di Rocco C (2008) The natural history of the Chiari type I anomaly. J Neurosurg Pediatr 2:179-187

35. Singhal A, Bowen-Roberts T, Steinbok P, Cochrane D, Byrne AT, Kerr JM (2011) Natural history of untreated syringomyelia in pediatric patients. Neurosurg Focus 31:E13

36. Strahle J, Muraszko KM, Kapurch J, Bapuraj JR, Garton HJ, Maher CO (2011) Natural history of Chiari malformation type I following decision for conservative treatment. J Neurosurg Pediatr 8:214-221

37. Ciaramitaro P, Ferraris M, Massaro F, Garbossa D (2019) Clinical diagnosis-part I: what is really caused by Chiari I. Childs Nerv Syst 35:1673-1679

38. Novegno F (2019) Clinical diagnosis-part II: what is attributed to Chiari I. Childs Nerv Syst 35:1681-1693

39. Mehta A, Chilakamarri P, Zubair A, Kuruvilla D (2018) Chiari headache. Curr Pain Headache Rep 22:49

40. Victorio MC, Khoury CK (2016) Headache and Chiari I malformation in children and adolescents. Semin Pediatr Neurol 23:35-39

41. Kawasaki Y, Uchida S, Onishi K, Toyokuni M, Okanari K, Fujiki M (2017) Intraoperative neurophysiologic monitoring for prediction of postoperative neurological improvement in a child with Chiari type I malformation. J Craniofac Surg 28:1837-1841

42. Roser F, Ebner FH, Liebsch M, Tatagiba MS, Naros G (2016) The role of intraoperative neuromonitoring in adults with Chiari I malformation. Clin Neurol Neurosurg 150:27-32

43. Leu RM (2015) Sleep-related breathing disorders and the Chiari 1 malformation. Chest 148:1346-1352

44. Losurdo A, Dittoni S, Testani E, Di Blasi C, Scarano E, Mariotti P, Paternoster G, Di Rocco C, Massimi L, Della Marca G (2013) Sleep disordered breathing in children and adolescents with Chiari malformation type I. J Clin Sleep Med 9:371-377

45. Zaffanello M, Sala F, Sacchetto L, Gasperi E, Piacentini G (2017) Evaluation of the central sleep apnea in asymptomatic children with Chiari 1 malformation: an open question. Childs Nerv Syst 33:829-832

46. Amin R, Sayal P, Sayal A, Massicote C, Pham R, Al-Saleh S, Drake J, Narang I (2015) The association between sleep-disordered 
breathing and magnetic resonance imaging findings in a pediatric cohort with Chiari 1 malformation. Can Respir J 22:31-36

47. Massimi L, Pennisi G, Frassanito P, Tamburrini G, Di Rocco C, Caldarelli M (2019) Chiari type I and hydrocephalus. Childs Nerv Syst 35:1701-1709

48. Hayhurst C, Osman-Farah J, Das K, Mallucci C (2008) Initial management of hydrocephalus associated with Chiari malformation type I-syringomyelia complex via endoscopic third ventriculostomy: an outcome analysis. J Neurosurg 108:1211-1214

49. Massimi L, Pravatà E, Tamburrini G, Gaudino S, Pettorini B, Novegno F, Colosimo C Jr, Di Rocco C (2011) Endoscopic third ventriculostomy for the management of Chiari I and related hydrocephalus: outcome and pathogenetic implications. Neurosurgery 68:950-956

50. Valentini LG, Saletti V, Erbetta A, Chiapparini L, Furlanetto M (2019) Chiari 1 malformation and untreated sagittal synostosis: a new subset of complex Chiari? Childs Nerv Syst 35:1741-1753

51. Afshari FT, Solanki GA, Lo WB, Rodrigues D (2020) Posterior calvarial augmentation for Chiari malformation type 1 refractory to foramen magnum decompression. World Neurosurg 139:70-74

52. Thompson DN, Hayward RD, Harkness WJ, Bingham RM, Jones BM (1995) Lessons from a case of kleeblattschädel. Case report. J Neurosurg 82:1071-1074

53. Massimi L, Peraio S, Peppucci E, Tamburrini G, Di Rocco C (2011) Section of the filum terminale: is it worthwhile in Chiari type I malformation? Neurol Sci 32 Suppl 3:S349-S351

54. Glenn C, Cheema AA, Safavi-Abbasi S, Gross NL, Martin MD, Mapstone TB (2015) Spinal cord detethering in children with tethered cord syndrome and Chiari type 1 malformations. J Clin Neurosci 22:1749-1752

55. Steinbok P, MacNeily AE, Hengel AR, Afshar K, Landgraf JM, Hader W, Pugh J (2016) Filum section for urinary incontinence in children with occult tethered cord syndrome: a randomized, controlled pilot study. J Urol 195(4 Pt 2):1183-1188

56. Milano JB, Barcelos ACES, Onishi FJ, Daniel JW, Botelho RV, Dantas FR, Neto ER, de Freitas Bertolini E, Mudo ML, Brock RS, de Oliveira RS, Joaquim AF (2020) The effect of filum terminale sectioning for Chiari 1 malformation treatment: systematic review. Neurol Sci 41:249-256

57. Valentini LG, Selvaggio G, Visintini S, Erbetta A, Scaioli V, Solero CL (2011) Tethered cord: natural history, surgical outcome and risk for Chiari malformation 1 (CM1): a review of 110 detethering. Neurol Sci 32(Suppl 3):S353-S356

58. Jiang E, Sha S, Yuan X, Zhu W, Jiang J, Ni H, Liu Z, Qiu Y, Zhu Z (2018) Comparison of clinical and radiographic outcomes for posterior fossa decompression with and without duraplasty for treatment of pediatric Chiari I malformation: a prospective study. World Neurosurg 110:e465-e472

59. Foreman P, Safavi-Abbasi S, Talley MC, Boeckman L, Mapstone TB (2012) Perioperative outcomes and complications associated with allogeneic duraplasty for the management of Chiari malformations type I in 48 pediatric patients. Neurosurg Pediatr 10:142-149

60. Martínez-Lage JF, Pérez-Espejo MA, Palazón JH, López Hernández F, Puerta P (2006) Autologous tissues for dural grafting in children: a report of 56 cases. Childs Nerv Syst 22:139-144

61. Noguchi-Shinohara M, Hamaguchi T, Kitamoto T, Sato T, Nakamura Y, Mizusawa H, Yamada M (2007) Clinical features and diagnosis of dura mater graft associated Creutzfeldt Jakob disease. Neurology 69:360-367

62. Greenberg JK, Milner E, Yarbrough CK, Lipsey K, Piccirillo JF, Smyth MD, Park TS, Limbrick DD Jr (2015) Outcome methods used in clinical studies of Chiari malformation type I: a systematic review. J Neurosurg 122:262-272

63. Furtado SV, Thakar S, Hegde AS (2011) Correlation of functional outcome and natural history with clinicoradiological factors in surgically managed pediatric Chiari I malformation. Neurosurgery 68: 319-327
64. Kennedy BC, Kelly KM, Phan MQ, Bruce SS, McDowell MM, Anderson RC, Feldstein NA (2015) Outcomes after suboccipital decompression without dural opening in children with Chiari malformation type I. J Neurosurg Pediatr 16:150-158

65. Massimi L, Frassanito P, Bianchi F, Tamburrini G, Caldarelli M (2019) Bony decompression vs duraplasty for Chiari I malformation: does the eternal dilemma matter? Childs Nerv Syst 35:1827-1838

66. Massimi L, Frassanito P, Chieffo D, Tamburrini G, Caldarelli M (2019) Bony decompression for Chiari malformation type I: longterm follow-up. Acta Neurochir Suppl 125:119-124

67. Mazzola CA, Fried AH (2003) Revision surgery for Chiari malformation decompression. Neurosurg Focus 15:E3

68. Alexander H, Tsering D, Myseros JS, Magge SN, Oluigbo C, Sanchez CE, Keating RF (2019) Management of Chiari I malformations: a paradigm in evolution. Childs Nerv Syst 35:1809-1826

69. Noureldine MHA, Shimony N, Jallo G, Groves ML (2019) Scoliosis in patients with Chiari malformation type I. Childs Nerv Syst 35:1853-1862

70. Strahle JM, Taiwo R, Averill C, Torner J, Gewirtz JI, Shannon CN, Bonfield CM, Tuite GF, Bethel-Anderson T, RCE A, Kelly MP, Shimony JS, Dacey RG, Smyth MD, Park TS, Limbrick DD, ParkReeves Syringomyelia Research Consortium (2020) Radiological and clinical associations with scoliosis outcomes after posterior fossa decompression in patients with Chiari malformation and syrinx from the Park-Reeves Syringomyelia Research Consortium. J Neurosurg Pediatr 10:1-7

71. Chatterjee S, Shivhare P, Verma SG (2019) Chiari malformation and atlantoaxial instability: problems of co-existence. Childs Nerv Syst 35:1755-1761

72. Ho WSC, Brockmeyer DL (2019) Complex Chiari malformation: using craniovertebral junction metrics to guide treatment. Childs Nerv Syst 35:1847-1851

73. Goel A (2018) Basilar invagination, syringomyelia and Chiari formation and their relationship with atlantoaxial instability. Neurol India 66:940-942

74. Goel A, Kaswa A, Shah A (2019) Atlantoaxial fixation for treatment of chiari formation and syringomyelia with no craniovertebral bone anomaly: report of an experience with 57 cases. Acta Neurochir Suppl 125:101-110

75. Chotai S, Chan EW, Ladner TR, Hale AT, Gannon SR, Shannon CN, Bonfield CM, Naftel RP, Wellons JC (2020) Timing of syrinx reduction and stabilization after posterior fossa decompression for pediatric Chiari malformation type I. J Neurosurg Pediatr 24:1-7

76. Hale AT, Adelson PD, Albert GW, Aldana PR, Alden TD, Anderson RCE, Bauer DF, Bonfield CM, Brockmeyer DL, Chern JJ, Couture DE, Daniels DJ, Durham SR, Ellenbogen RG, Eskandari R, George TM, Grant GA, Graupman PC, Greene S, Greenfield JP, Gross NL, Guillaume DJ, Heuer GG, Iantosca M, Iskandar BJ, Jackson EM, Johnston JM, Keating RF, Leonard JR, Maher CO, Mangano FT, McComb JG, Meehan T, Menezes AH, O’Neill B, Olavarria G, Park TS, Ragheb J, Selden NR, Shah MN, Smyth MD, Stone SSD, Strahle JM, Wait SD, Wellons JC, Whitehead WE, Shannon CN, Limbrick DD, Park-Reeves Syringomyelia Research Consortium Investigators (2020) Factors associated with syrinx size in pediatric patients treated for Chiari malformation type I and syringomyelia: a study from the Park-Reeves Syringomyelia Research Consortium. J Neurosurg Pediatr 6:1-11

77. Massimi L, Novegno F, di Rocco C (2011) Chiari type I malformation in children. Adv Tech Stand Neurosurg 37:143-211

78. Joseph RN, Batty R, Raghavan A, Sinha S, Griffiths PD, Connolly DJ (2013) Management of isolated syringomyelia in the paediatric population-a review of imaging and follow-up in a single Centre. Br J Neurosurg 27:683-686

79. Magge SN, Smyth MD, Governale LS, Goumnerova L, Madsen J, Munro B, Nalbach SV, Proctor MR, Scott RM, Smith ER (2011) 
Idiopathic syrinx in the pediatric population: a combined center experience. J Neurosurg Pediatr 7:30-36

80. Rodriguez A, Kuhn EN, Somasundaram A, Couture DE (2015) Management of idiopathic pediatric syringohydromyelia. J Neurosurg Pediatr 16:452-457
81. Soleman J, Roth J, Constantini S (2019) Direct syrinx drainage in patients with Chiari I malformation. Childs Nerv Syst 35:1863-1868

Publisher's note Springer Nature remains neutral with regard to jurisdictional claims in published maps and institutional affiliations.

\section{Affiliations}

Luca Massimi $^{1}$ (D) Paola Peretta ${ }^{2} \cdot$ Alessandra Erbetta $^{3} \cdot$ Alessandra Solari $^{4} \cdot$ Mariangela Farinotti $^{4}$. Palma Ciaramitaro ${ }^{5}$ - Veronica Saletti ${ }^{6} \cdot$ Massimo Caldarelli $^{1} \cdot$ Alexandre Casagrande Canheu $^{7} \cdot$ Carlo Celada $^{8}$. Luisa Chiapparini ${ }^{3}$. Daniela Chieffo ${ }^{9}$. Giuseppe Cinalli ${ }^{10}$. Federico Di Rocco $^{11}$. Marika Furlanetto ${ }^{12}$. Flavio Giordano ${ }^{13}$. George Jallo ${ }^{14}$. Syril James ${ }^{15}$. Paola Lanteri ${ }^{16}$. Christian Lemarchand ${ }^{17}$. Martina Messing-Jünger ${ }^{18}$. Cecilia Parazzini ${ }^{19}$. Giovanna Paternoster ${ }^{15}$. Gianluca Piatelli ${ }^{20}$ - Maria. A. Poca ${ }^{21}$. Prab Prabahkar ${ }^{22}$. Federica Ricci ${ }^{23}$. Andrea Righini ${ }^{19}$. Francesco Sala ${ }^{24}$ • Juan Sahuquillo ${ }^{21}$. Marcus Stoodley ${ }^{25}$. Giuseppe Talamonti ${ }^{26}$. Dominic Thompson ${ }^{27} \cdot$ Fabio Triulzi $^{28} \cdot$ Mino Zucchelli $^{29} \cdot$ Laura Valentini $^{12} \cdot$ International $^{2}$ Experts - Jury of the Chiari \& Syringomyelia Consensus Conference, "Milan, November 11-13, 2019"

1 Pediatric Neurosurgery, Fondazione Policlinico Universitario A. Gemelli IRCCS, Largo A. Gemelli, 8, 00168 Rome, Italy

2 Pediatric Neurosurgery, AOU Citta' della Salute e della Scienza di Torino, Torino, Italy

3 Department of Neuroradiology, Fondazione IRCCS Istituto Neurologico Carlo Besta, Milan, Italy

4 Neuroepidemiology Unit - Scientific Directorate, Fondazione IRCCS Istituto Neurologico Carlo Besta, Milan, Italy

5 Department of Neuroscience, AOU Citta' della Salute e della Scienza di Torino, Torino, Italy

6 Department of Pediatric Neurology, Fondazione IRCCS Istituto Neurologico Carlo Besta, Milan, Italy

7 Pediatric Neurosurgery Division, Universidade Estadual de Londrina, Londrina, Brazil

8 “Associazione Italiana Siringomielia e Arnold Chiari”, Garino, Italy

9 Clinical Psychology Unit, Fondazione Policlinico Universitario A Gemelli IRCCS and UCSC, Rome, Italy

10 Pediatric Neurosurgery, Santobono-Pausilipon Children's Hospital, Naples, Italy

11 Pediatric Neurosurgery Department, Université de Lyon, INSERM U1033, Hopital Femme Mère Enfant, Lyon, France

12 Department of Neurosurgery, Fondazione IRCCS Istituto Neurologico Carlo Besta, Milan, Italy

13 Department of Neurosurgery, Meyer Pediatric Hospital, Florence, Italy

14 Institute for Brain Protection Sciences, Johns Hopkins All Children's Hospital, St. Petersburg, FL, USA

15 Department of Pediatric Neurosurgery, Necker Enfants Malades Hospital, Paris, France
16 Department of Diagnostic and Technology, Neurophysiopathology Unit, Fondazione IRCCS Istituto Neurologico Carlo Besta, Milan, Italy

17 Conseil Scientifique APAISER S\&C, Treillières, France

18 Pädiatrische Neurochirurgie, Asklepios Kinderklinik, Sankt Augustin, Germany

19 Department of Pediatric Radiology and Neuroradiology, Children Hospital V. Buzzi, Milan, Italy

20 Department of Neurosurgery, Gaslini Children's Hospital, Genoa, Italy

21 Neurosurgery and Pediatric Neurosurgery, Vall d'Hebron Hospital Universitari, Neurotrauma and Neurosurgery Research Unit, and Universitat Autònoma de Barcelona, Barcelona, Spain

22 Department of Neurology, Great Ormond Street Hospital for Children, London, UK

23 Pediatric Neuropsychiatric Unit, AOU Citta' della Salute e della Scienza di Torino, Torino, Italy

24 Section of Neurosurgery, Department of Neurosciences, Biomedicine and Movement Sciences, University Hospital, Verona, Italy

25 Department of Clinical Medicine, Macquarie University Clinical Associates, Sidney, Australia

26 Department of Neurosurgery, ASST Niguarda, Milan, Italy

27 Department of Neurosurgery, Great Ormond Street Hospital for Children, London, UK

28 Department of Pathophysiology and Transplantation, Neuroradiology Unit, University of Milan, Fondazione IRCCS Cà Granda, Ospedale Maggiore Policlinico, Milan, Italy

29 Neurochirurgia Pediatrica, IRCCS Istituto delle Scienze Neurologiche di Bologna, Bologna, Italy 